\title{
Spondias mombin promotes gastric mucosa and lipid profile status in gastric ulceration
}

\author{
AKINLOLU, A. A. ${ }^{1 *}$, GHAZALI, K. O. ${ }^{2}$, AMEEN, O. M. $^{3}$ and ODEWABI, A. O. ${ }^{4}$ \\ ${ }^{1} \mathrm{PhD}$ Anatomy (in-view), Department of Anatomy, Faculty of Basic Medical Sciences, \\ University of Ilorin, P.M.B. 1515, Ilorin, Kwara State, Nigeria \\ ${ }^{2} \mathrm{PhD}$ Anatomy (in-view), Department of Anatomy, University of Ilorin, P.M.B. 1515, Ilorin, Kwara State, Nigeria \\ ${ }^{3} \mathrm{PhD}$ Chemistry (in-view), Department of Anatomy, University of Ilorin, \\ P.M.B. 1515, Ilorin, Kwara State, Nigeria \\ ${ }^{4}$ Higher National Diploma (Medical Laboratory Sciences), M.Sc Biochemistry, Olabisi Onabanjo University \\ Teaching Hospital, Akarigbo Street, Shagamu, Ogun State, Nigeria \\ *E-mail: a3akin@gmail.com; akinlolu.aa@unilorin.edu.ng
}

\begin{abstract}
Introduction: Spondias mombin has been reported to possess medicinal properties. Material and Methods: This study evaluated the anti-ulcer properties of Spondias mombin. Rats of Group I received physiological saline only while $40 \mathrm{mg} / \mathrm{kg}$ /bodyweight of Indomethacin (an ulcerogen) was administered to rats of Groups II - VI. Four hours after administrations of the ulcerogen; rats of Groups III - VI were treated daily with oral administrations of 250,500 and $1000 \mathrm{mg} / \mathrm{kg} /$ bodyweight of Spondias mombin bark extract and $40 \mathrm{mg} / \mathrm{kg} /$ bodyweight of Omeprazole respectively for four days. Rats were euthanized on Days 1 (Group II) and 5 (Groups I and III - VI); stomach and liver samples were removed for evaluations of gastric acidity, histo-pathological and lipid profile status. Results: Analyses of gastric acidity and lipid profile status in the stomach and liver samples of rats of Group II showed statistically significant higher levels $(P \leq 0.05)$ of gastric acidity, total cholesterol, low density lipoprotein-cholesterol and triglycerides but lower high density lipoprotein-cholesterol levels $(\mathrm{P} \leq 0.05)$ when compared to rats of Groups I, and III - VI. Histopathological evaluations showed dose-dependent restorations of stomach and liver histology to pre-ulceration states in rats of Groups III - VI. Conclusions: This study concluded that Spondias mombin administrations promoted histo-pathological restorations of the stomach and liver; and lipid profile status of male wistar rats in Indomethacin - induced gastric ulceration.
\end{abstract}

Keywords: spondias mombin, indomethacin, stomach, ulceration, rats.

\section{Introduction}

Ulceration refers to any break in the skin or mucus membrane and is classified according to the part of the digestive system in which it occurs. (RAMZI, VINAY and TURCKER, 1999; MAITY and CHATTOPADHYAY, 2008). Gastric ulcer occurs in the stomach and is characterized by the malfunctioning or non-availability of gastric juice for the breaking down of proteins into smaller polypeptides. (RAMZI, VINAY and TURCKER, 1999; MAITY and CHATTOPADHYAY, 2008). Peptic ulcer occurs in sections of the gastro intestinal tract exposed to gastric acid and pepsin such as the stomach and duodenum (RAMZI, VINAY and TURCKER, 1999).

The etiology of ulcerations is not clearly known. It results probably from an imbalance between aggressive (acid, pepsin and Helicobacter pylori infection) and defensive (gastric mucus and bicarbonate secretion, prostaglandins, cyclooxygenases, nitric oxide, innate resistance of the mucosal cells) factors; as well as factors such as genetic, psychosomatic, humoral and vascular derangements. (RAMZI, VINAY and TURCKER, 1999). Pathological examination of gastric ulcer could be evaluated in any part of the stomach, but is most commonly obtained from the lesser curvature. Histologically, there is a break in the superficial epithelium penetrating down to the muscularis mucosa with a fibrous base accompanied with increase in inflammatory cells. (RAMZI, VINAY and TURCKER, 1999).

Phospholipids of the gastric mucus gel layer act as primary barriers to acid-induced damage of the stomach by establishing the hydrophobicity of the stomach's epithelial cellular layer. (JOHN, 2000). Indomethacin belongs to the group of non-steroidal anti-inflammatory drugs (NSAIDs) which have been established to interact with surface-active phospholipids of the gastric mucosa, thereby reducing its hydrophobicity and the quality of its protection against ulcerogens. (JOHN, 2000).

Spondias mombin L. (Anacardiaceae) is a tree that is easily grown on farmlands and is up to $20 \mathrm{~m}$ in height. It is traditionally believed to possess purgative, antihelmintic, analgesic, haemostatic and antibacterial potentials. (GBOLADE, EKOR, AKINLOLU et al., 2008; GBOLADE, AKINLOLU and ODEWABI, 2011). Scientific studies have observed abortificient, anti-anaemic, anti-diabetic, hypoglycaemic and hypolipidemic potentials of Spondias mombin. (GBOLADE, EKOR, AKINLOLU et al., 2008; GBOLADE, AKINLOLU and ODEWABI et al., 2011). To the best of our knowledge after literature review, the anti- 
ulcer activity of the bark of Spondias mombin is yet to be reported.This study, therefore, tested the hypothesis that methanolic extract doses of the suckers of bark of Spondias mombin improves histo-pathological restoration and lipid profile status of adult wistar rats in indomethacin-induced gastric mucosa ulceration.

\section{Materials and Methods}

\subsection{Collection, authentication and preparation of plant extract}

Air-dried barks of Spondias mombin were purchased from Oja - Tuntun market at Ilorin, Kwara state, Nigeria. The collected samples were identified at the Department of Plant Biology of the University of Ilorin, Kwara State, Nigeria and deposited at the herbarium. The air-dried samples of the bark of Spondias mombin were pulverized and $0.5 \mathrm{~g}$ of the plant material was extracted with $70 \%$ methanol for 72 hours. The extract was filtered, concentrated with rotary evaporator and further dried on a water bath.

\subsection{Ethical approval, care and feeding of animals}

Thirty adult male wistar rats weighing between 100$150 \mathrm{~g}$ were obtained from the colony bred of the Physiology Department of University of Ibadan, Ibadan, Oyo State, Nigeria. Animals were fed during the experiment with growers feed from Bendel Feed and Flour Mill Ltd., Nigeria. The animals were caged under standard conditions in the well ventilated animal house of the Faculty of Basic Medical Sciences of University of Ilorin, Ilorin, Kwara State, Nigeria at room temperature of $25^{\circ} \mathrm{C}$. Water was supplied ad libitum to the rats. Ethical approval was sought and received from the ethical committee of the Faculty of Basic Medical Sciences of University of Ilorin, Ilorin, Kwara State, Nigeria on the usage of animals for experimental studies.

\subsection{Chemicals, reagents and laboratory equipments}

Indomethacin (Hovid, Nigeria), Omeprazole (Eprazole, China), Sodium dihydrogen phosphate $\left(\mathrm{NaH}_{2} \mathrm{PO}_{4}\right)$, Disodium hydrogen phosphate $\left(\mathrm{Na}_{2} \mathrm{HPO}_{4}\right)$, Hydrogen peroxide $\left(\mathrm{H}_{2} \mathrm{O}_{2}\right)$ and Trichloroacetic acid (TCA) were products of Aldrich Chemicals; Sulphuric (VI) acid $\left(\mathrm{H}_{2} \mathrm{SO}_{4}\right)$ and hydrochloric acid (HCI) were products of $\mathrm{BDH}$ Chemical Limited, Poole, England; Tris buffers, phosphoric acid and pyrogallol were products of Sigma Chemicals, St. Louis USA and assay kits for Total Cholesterol, High Density Lipoprotein - Cholesterol and Triglycerides (Randox Laboratories, United Kingdom). Spectrophotometer (Jenway Model 6405, UV/visible), centrifuge, $\mathrm{pH}$ meter (Rex model pHs 25), Norm-jet needles and syringes (Normjet Inc. Tuttlinger, Germany) and anti-coagulant tubes (Sterling products, England).

\subsection{Administrations of doses of drugs/extracts to animals}

Doses of drugs or extract were administered to wistar rats according to described protocol on animal models of gastric ulceration experimentation by Wiley Interscience Protocol. Rats of Control Group I received $2 \mathrm{mls}$ of Normal Saline daily for five days (Days $1-5$ ). On Day 1 , a single oral dose of $80 \mathrm{mg} / \mathrm{kg}$ bodyweight of Indomethacin administered to rats of Group II - VI that have been deprived of food for the previous 18-24 hours, produced erosive lesions in the gastric mucosa within 4-6 hours. Rats of Group II were euthanized after induction of gastric ulceration on Day 1 for scoring of ulceration, gastric acidity assay, histological and biochemical evaluations.

Treatments of gastric ulceration was started on Day 1 with a single oral administrations of 250,500 and $1000 \mathrm{mg} /$ $\mathrm{kg}$ bodyweight of Spondias mombin bark extract and $40 \mathrm{mg} / \mathrm{kg}$ bodyweight of Omeprazole to rats of Groups III - VI respectively, 4 hours after administration of $80 \mathrm{mg} /$ $\mathrm{kg}$ bodyweight of Indomethacin. The treatment procedures were continued daily for another three days (Days $2-4$ ). Administered drugs or extract doses were freshly prepared daily. Upon completion of treatment procedures on Day 4, the animals were left without food but provided with water ad libitum 14 hours prior to euthanasia. Thirty minutes prior to euthanasia, $1 \mathrm{ml}$ of $1 \%$ Evan's blue in saline was injected intravenously into the tail vein of rats of Group II (on Day 1); Groups I and III - VI (on Day 5 ) using a $1 \mathrm{ml} \mathrm{25-G,} \mathrm{5/8-}$ inch needle to aid identification and evaluation of lesions and ulcerations.

\subsection{Scoring system for gastrointestinal lesions in the rats}

Score Characteristics

0 No ulcerations or mucosal damage

1 Up to 15 small mucosal ulcerations $(<1 \mathrm{~mm}$ in diameter) observable only as slight depressions in reflected light.

2 Small and medium mucosal ulcerations ( $1-4 \mathrm{~mm}$ in diameter); no ulcerations $>4 \mathrm{~mm}$ in diameter.

3 Predominantly medium and large ulcerations; ulcerations $>4 \mathrm{~mm}$ in diameter; no intestinal adhesions.

4 Large ulcerations; exhibit signs of perforations and adhesions which make it difficult to remove the intestinal tracts.

$5 \quad$ Necropsy of dead or euthanized animals reveals evidence of massive peritonitis resulting from intestinal perforations.

\subsection{Evaluations of gastric acidity in stomach tissues}

The stomach contents were collected into a centrifuge bottle, mixed properly with Normal Saline and the mixture centrifuged at 2000 revolutions per minute for 10 minutes. One drop of phenolphthalein indicator was then added to the supernatant. Imls of the supernatant (Volume of Acid $-\mathrm{V}_{\mathrm{A}}$ ) was pipetted and titrated against $0.01 \mathrm{M} \mathrm{NaOH}$ (Concentration of the Base $-\mathrm{C}_{\mathrm{B}}$ ). The colour change was noted (end point) and the Volume of Base $\left(\mathrm{V}_{\mathrm{B}}\right)$ used was recorded. Gastric acidity was calculated using $C_{A} V_{A}=C_{B} V_{B}$.

\subsection{Histological analyses}

The stomach and liver samples of rats of Groups I - VI were excised and removed for histo-pathological evaluations as earlier described. (AKINLOLU, AYOOLA, OTULANA et al., 2008). 


\subsection{Evaluations of lipid profile status in liver tissues of rats of groups $I$ - VI}

The liver was excised and removed for each rat of Groups I - VI, cut into small pieces, placed in a mortar to which $0.1 \mathrm{M}$ phosphate buffer (extracting solution) of at least four times the volume of the organ was added. The organ was homogenized into fine solution with the use of mortar and pestle. The homogenate was poured into a test tube and centrifuged at 5000 revolutions per minute for 5 minutes. The supernatant was carefully removed and the residue was discarded. The supernatant served as the sample for the estimation of lipid profile status in rats of Groups I - VI. The Total Cholesterol, High Density Lipoprotein - Cholesterol, Low Density Lipoprotein - Cholesterol and Triglycerides levels were determined in liver samples of rats of Groups I - VI based on the protocols described in assay kits of Randox Laboratories, United Kingdom).

\subsection{Statistical analyses}

The Mean \pm S.E.M (S.E.M. = Standard Error of Mean) value of each of the measured parameters of gastric acidity and lipid profile assays in rats of Control Group I (which received Normal Saline) were compared with those of Groups II - VI (which received Indomethacin only, Indomethacin plus extract doses or Indomethacin plus Omeprazole) for any significant difference using the Student's t-test for unpaired samples. P values of 0.05 (or less) were taken as statistically significant.

\section{Results}

Results of the statistical analyses of the effects of extract doses of Spondias mombin and $40 \mathrm{mg} / \mathrm{kg} /$ bodyweight of Omeprazole on Ulcer Index, Gastric Acidity, Total Cholesterol, HDL-Cholesterol and Triglycerides levels in liver samples of rats of Groups I - VI are as presented in Tables 1 and 2. Observations of histological evaluations of the stomach and liver samples of rats of Groups I - VI are as presented in Figures 1-6.

\section{Discussions}

Indomethacin is an established ulcerogen, especially in an empty stomach (AKINLOLU, SADIQ, AYOOLA et al., 2006; AKINLOLU, AYOOLA, OTULANA et al., 2008). Indomethacin induced ulceration occurs mostly in the glandular (mucosal) part of the stomach. (RAMZI, VINAY and TURCKER, 1999; JOHN, 2000). Although, the mechanisms underlying the ulcerogenicity of indomethacin are not completely understood; it has been known that indomethacin induces gastric mucosa ulceration through the inhibition of the release of protective factors like cyclooxygenases, prostaglandin E2 (PGE2), bicarbonate, mucus and antioxidants; while aiding vasoconstriction (SEN, CHAKRABORTY and MAZUMDER, 2009) and the increase of aggressive factors such as acid and oxidants. (JOHN, 2000; MAITY and CHATTOPADHYAY, 2008; SULEYMAN, ALBAYRAK, BILICI et al., 2010). Prostaglandins are potent anti-secretory and anti-ulcer agents which serve protective functions in the stomach by maintaining gastric micro circulation via mucus and bi carbonate stimulation (RAMZI, VINAY and TURCKER, 1999; JOHN, 2000; MAITY and CHATTOPADHYAY, 2008).

Analyses of gastric acid assays and histo-pathological examinations showed dose-dependent reduction of gastric acidity, restorations of the gastric mucosa layer and cytoarchitectural components of the liver to pre-ulceration states in rats of Groups III - VI. (Table 1 and Figures 1-6). The best results were observed in rats of Group V treated with

Table 1. Analyses of the effects of Spondias mombin on Ulcer Index and Gastric Acidity.

\begin{tabular}{clcc}
\hline Groups of rats & \multicolumn{1}{c}{ Dose of drugs/extract } & Ulcer index & Gastric acidity (meq/1) \\
\hline II & $80 \mathrm{mg} / \mathrm{kg}$ bodyweight Indomethacin & $3.25 \pm 0.25$ & 0.06 \\
III & $250 \mathrm{mg} / \mathrm{kg}$ bodyweight Spondias mombin & $0.7 \pm 0.5$ & 0.21 \\
IV & $500 \mathrm{mg} / \mathrm{kg}$ bodyweight Spondias mombin & $0.6 \pm 2.55$ & 0.02 \\
V & $1000 \mathrm{mg} / \mathrm{kg}$ bodyweight Spondias mombin & $0.5 \pm 0.25$ & 0.02 \\
VI & $40 \mathrm{mg} / \mathrm{kg}$ bodyweight Omeprazole & $0.36 \pm 0.23$ & 0.01 \\
\hline
\end{tabular}

bw = bodyweight.

Table 2. Statistical analyses of Total Cholesterol, HDL-Cholesterol, LDL-cholesterol and Triglycerides Levels in Liver Samples of Rats of Groups I - VI.

\begin{tabular}{|c|c|c|c|c|c|}
\hline $\begin{array}{l}\text { Groups } \\
\text { of rats }\end{array}$ & Doses of drugs/extract & $\begin{array}{l}\text { Total cholesterol } \\
(\mathrm{mg} / \mathrm{dl}) \pm \text { S.E.M. }\end{array}$ & $\begin{array}{l}\text { HDL-cholesterol } \\
(\mathrm{mg} / \mathrm{dl}) \pm \text { S.E.M. }\end{array}$ & $\begin{array}{l}\text { LDL-cholesterol } \\
(\mathrm{mg} / \mathrm{dl}) \pm \text { S.E.M. }\end{array}$ & $\begin{array}{c}\text { Triglycerides } \\
(\mathrm{mg} / \mathrm{dl}) \pm \text { S.E.M. }\end{array}$ \\
\hline $\mathrm{I}$ & $2 \mathrm{mls}$ Normal Saline & 18.92 & 8.00 & 10.92 & 30.98 \\
\hline II & $40 \mathrm{mg} / \mathrm{kg}$ bw Indomethacin & 261.37 & 10.59 & 191.9 & 278.91 \\
\hline III & $\begin{array}{l}250 \mathrm{mg} / \mathrm{kg} \text { bw Spondias } \\
\text { mombin }\end{array}$ & 30.55 & 8.22 & 14.44 & 40.18 \\
\hline IV & $\begin{array}{l}500 \mathrm{mg} / \mathrm{kg} \text { bw Spondias } \\
\text { mombin }\end{array}$ & 137.4 & 16.37 & 96.7 & 121.5 \\
\hline $\mathrm{V}$ & $\begin{array}{l}1000 \mathrm{mg} / \mathrm{kg} \text { bw Spondias } \\
\text { mombin }\end{array}$ & 63.4 & 13.61 & 35.7 & 73.31 \\
\hline VI & $40 \mathrm{mg} / \mathrm{kg}$ bw Omeprazole & 23.49 & 8.69 & 14.8 & 34.67 \\
\hline
\end{tabular}

bw = bodyweight, S.E.M. = Standard Error of Mean. 

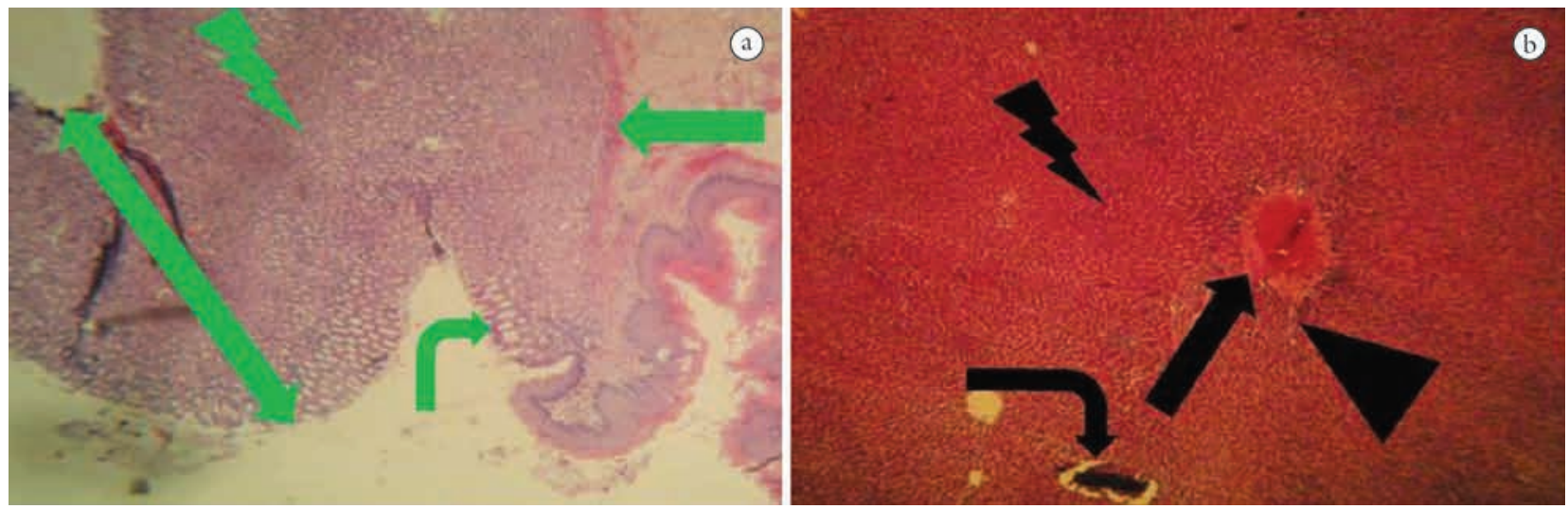

Figure 1. a) Photomicrograph sample of the stomach of rats of Group I which received physiological saline only. Heamatoxylin and Eosin X 100. Up-Down arrow extends through the length of gastric mucosa layer, Bent arrow points to gastric pits and glands, Arrow points to muscularis mucosae and the Lightning Bolt points to peptic cells. All identification shapes are in Green colour. The cytoarchitectural components of the stomach appeared normal. b) Photomicrograph sample of the liver of rats of Group I which received physiological saline only. Heamatoxylin and Eosin X 100. Bent arrow points to kupffer cells, Arrow points to central vein, the Lightning Bolt points to hepatic cells and the apex of the Triangle points to a sinusoid. All identification shapes are in Black colour. The cytoarchitectural components of the liver appeared normal.
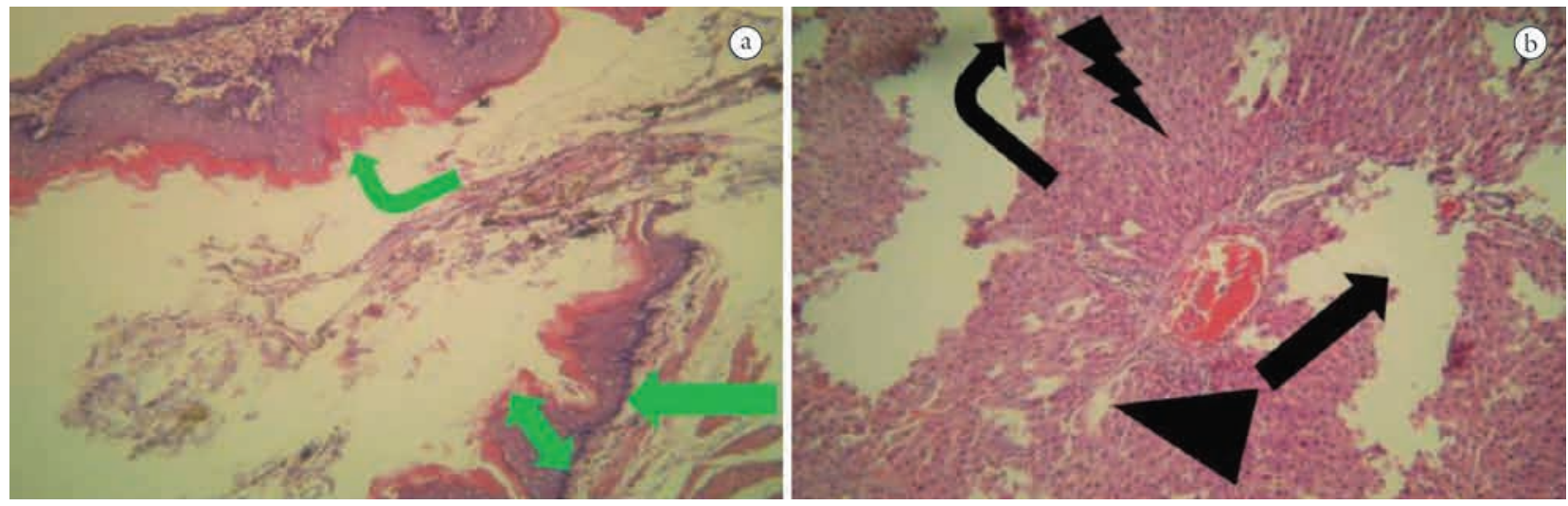

Figure 2. a) Photomicrograph sample of the stomach of rats of Group II which received $40 \mathrm{mg} / \mathrm{kg} / \mathrm{bodyweight}$ of Indomethacin only. Heamatoxylin and Eosin X 100. Up-Down arrow extends through the length of gastric mucosa layer, Bent arrow points to gastric pits and glands and the Arrow points to muscularis mucosae. All identification shapes are in Green colour. The cytoarchitectural components of the stomach appeared disrupted. The mucosa components were eroded and there was excessive heamorrhage of the mucosa. $\mathrm{b}$ ) Photomicrograph sample of the liver of rats of Group II which received $40 \mathrm{mg} / \mathrm{kg} /$ bodyweight of Indomethacin only. Heamatoxylin and Eosin X 100. Bent arrow points to kupffer cells, Arrow points to central vein, the Lightning Bolt points to hepatic cells and the apex of the Triangle points to a sinusoid. All identification shapes are in Black colour. The cytoarchitectural components of the liver appeared disrupted. There were excessive heamorrhage, severe fatty degeneration and enlargement of the central vein.

$1000 \mathrm{mg} / \mathrm{kg} /$ bodyweight of Spondias mombin bark extract. (Table 1 and Figures 1-6). The phytochemical analyses of the methanolic extract of Spondias mombin bark showed the presence of phenolic compounds, gallotannins and phenolic acids. (GBOLADE, AKINLOLU and ODEWABI, 2011). Phenolic compounds promote mucosa restoration, scavenge free radicals, inhibit calcium ion influx, reduce acid secretion and block the production of pepsinogens to provide cytoprotection. (MAITY and CHATTOPADHYAY, 2008; SABIHA, MOHD, ASIF et al., 2011).

Tannins being an astringent with vasoconstricting effects (SABIHA, MOHD, ASIF et al., 2011) might have precipitated microproteins on the sites of ulcers thereby forming a non-penetrable protective pellicle over the lining to prevent absorption of toxic substances and resisted the attack of proteolytic enzymes. (JOHN and ONABANJO, 1990; SABIHA, MOHD, ASIF et al., 2011).

Phospholipids of the gastric mucus gel layer act as primary barriers to acid-induced damage of the stomach by establishing the hydrophobicity of the stomach's epithelial cellular layer. (JOHN, 2000). Indomethacin interacts with surface-active phospholipids of the gastric mucosa, thereby reducing its hydrophobicity and the quality of its protection against ulcerogens. (JOHN, 2000). Statistically significant higher levels $(\mathrm{P} \leq 0.05)$ of total cholesterol, low density lipoprotein-cholesterol and triglycerides levels but 

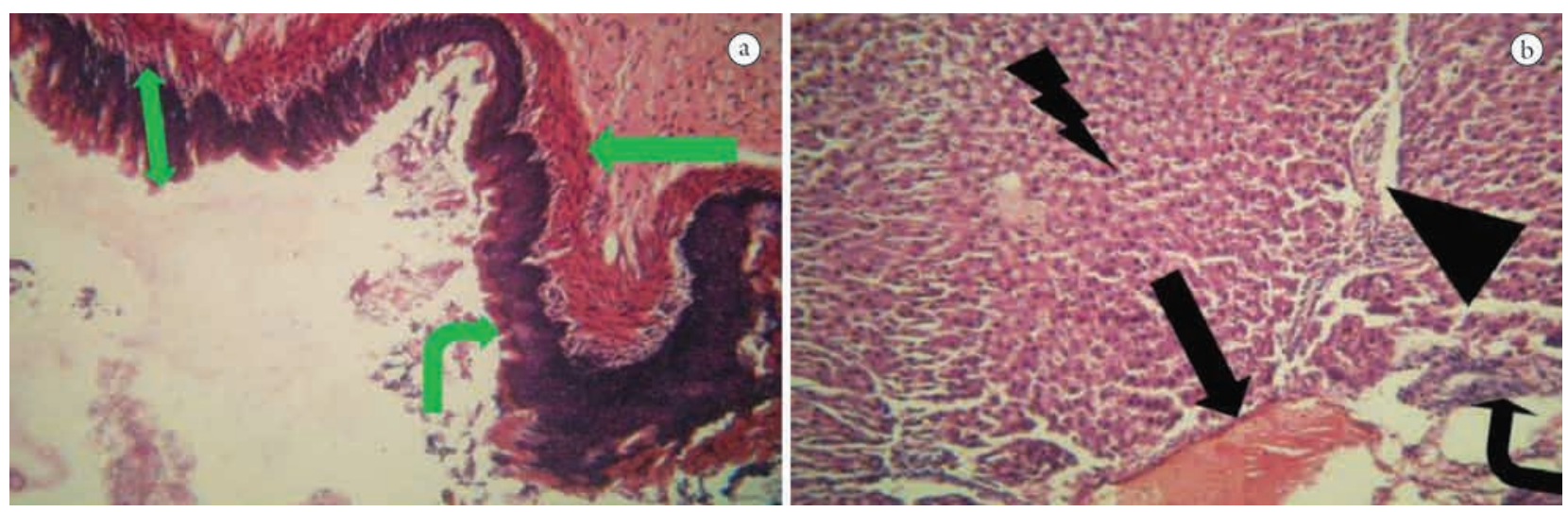

Figure 3. a) Photomicrograph sample of the stomach of rats of Group III treated with $250 \mathrm{mg} / \mathrm{kg} / \mathrm{bodyweight} \mathrm{of} \mathrm{Spondias} \mathrm{mombin.}$ Heamatoxylin and Eosin X 100. Up-Down arrow extends through the length of gastric mucosa layer, Bent arrow points to gastric pits and glands and the Arrow points to muscularis mucosae. All identification shapes are in Green colour. The cytoarchitectural components of the stomach appeared mildly disrupted. There was mild heamorrhage of the mucosa layer. b) Photomicrograph sample of the liver of rats of Group III treated with $250 \mathrm{mg} / \mathrm{kg} /$ bodyweight of Spondias mombin. Heamatoxylin and Eosin X 100 . Bent arrow points to kupffer cells, Arrow points to central vein, the Lightning Bolt points to hepatic cells and the apex of the Triangle points to a sinusoid. All identification shapes are in Black colour. The cytoarchitectural components of the liver appeared mildly disrupted with focal fatty degeneration and enlargement of the central vein.
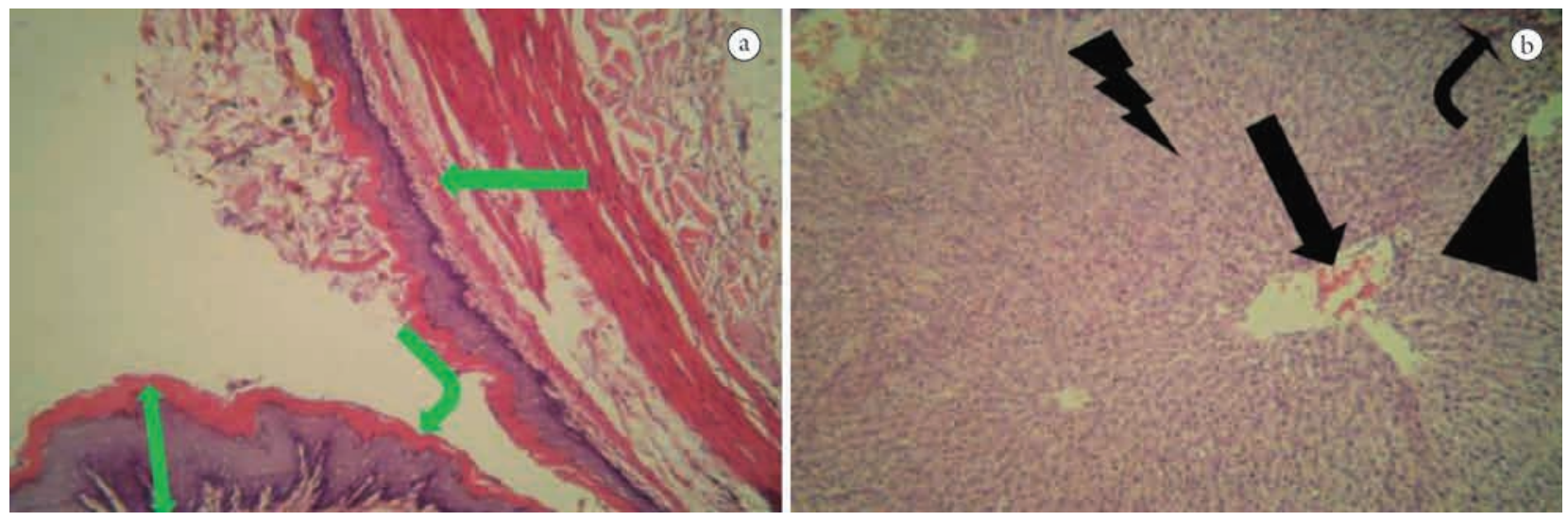

Figure 4. a) Photomicrograph sample of the stomach of rats of Group IV treated with $500 \mathrm{mg} / \mathrm{kg} / \mathrm{bodyweight} \mathrm{of} \mathrm{Spondias} \mathrm{mombin.}$ Heamatoxylin and Eosin X 100. Up-Down arrow extends through the length of gastric mucosa layer, Bent arrow points to gastric pits and glands and the Arrow points to muscularis mucosae. All identification shapes are in Green colour. The cytoarchitectural components of the stomach appeared normal though there was mild heamorrhage of the mucosa layer. b) Photomicrograph sample of the liver of rats of Group IV treated with $500 \mathrm{mg} / \mathrm{kg} /$ bodyweight of Spondias mombin. Heamatoxylin and Eosin X 100. Bent arrow points to kupffer cells, Arrow points to central vein, the Lightning Bolt points to hepatic cells and the apex of the Triangle points to a sinusoid. All identification shapes are in Black colour. The cytoarchitectural components of the liver appeared normal though with mild heamorrhage.

lower high density lipoprotein-cholesterol levels $(\mathrm{P} \leq 0.05)$ were observed in the liver samples of rats of Group II that received only $40 \mathrm{mg} / \mathrm{kg} /$ bodyweight of Indomethacin when compared to treated rats of Groups III - VI. (Table 2). However, the best results of lipid profile status were observed with the administration of $40 \mathrm{mg} / \mathrm{kg}$ bodyweight of Omeprazole when compared with rats treated with extract doses. (Table 2). This implied that administrations of treated with 250,500 and $1000 \mathrm{mg} / \mathrm{kg}$ bodyweight of Spondias mombin bark extract improved lipid profile status of male wistar rats in Indomethacin - induced gastric ulceration.

The precise mechanisms of action of Spondias mombin bark extract could not be fully determined in this study; however, its anti-ulcer properties could be due to its phenolic and tannins components and/or its ability to mobilize endogenous prostaglandins in gastric mucosa. (BORRELLI and IZZO, 2000; SEN, CHAKRABORTY and MAZUMDER, 2009).

\section{Conclusions}

This study concluded that administrations of 250, 500 and $1000 \mathrm{mg} / \mathrm{kg}$ bodyweight of Spondias mombin bark extract promoted histo-pathological restorations of the stomach and liver; and lipid profile status of male wistar rats in Indomethacin - induced gastric ulceration. 

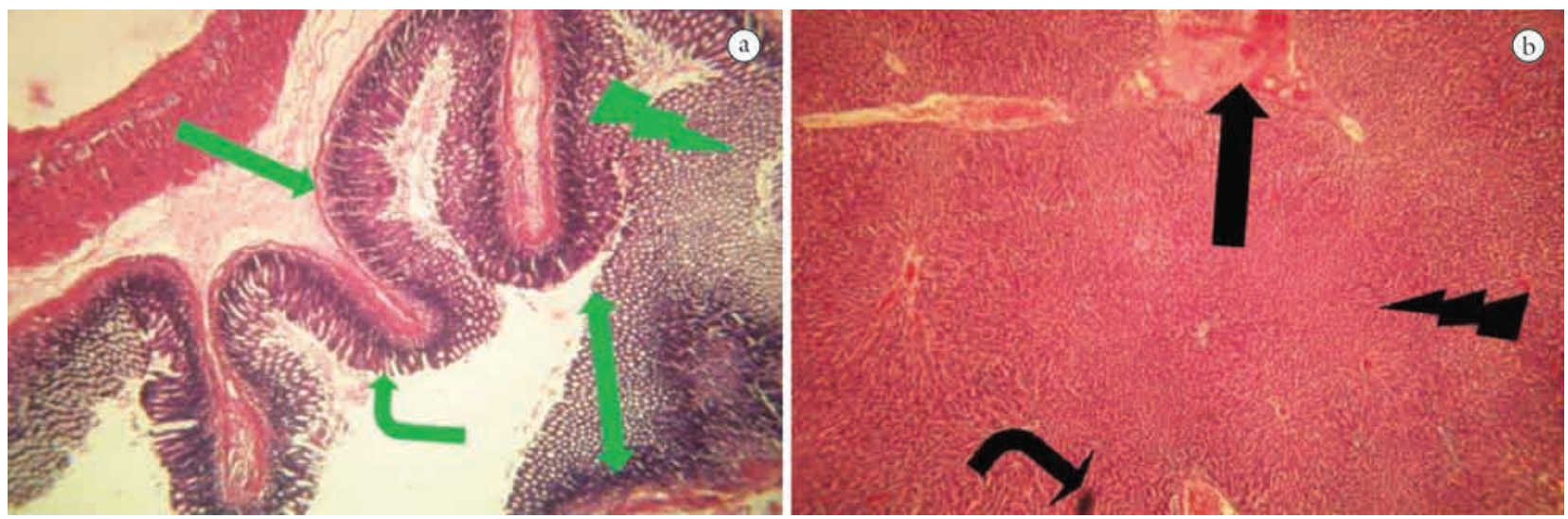

Figure 5. a) Photomicrograph sample of the stomach of rats of Group V treated with $1000 \mathrm{mg} / \mathrm{kg} /$ bodyweight of Spondias mombin. Heamatoxylin and Eosin X 100. Up-Down arrow extends through the length of gastric mucosa layer, Bent arrow points to gastric pits and glands, Arrow points to muscularis mucosae and the Lightning Bolt points to peptic cells. All identification shapes are in Green colour. The cytoarchitectural components of the stomach appeared normal indicating regeneration of disrupted mucosa following Indomethacin-induced gastric ulceration. b) Photomicrograph sample of the liver of rats of Group V treated with $1000 \mathrm{mg} /$ $\mathrm{kg}$ /bodyweight of Spondias mombin. Heamatoxylin and Eosin X 100. Bent arrow points to kupffer cells, Arrow points to central vein and the Lightning Bolt points to hepatic cells. All identification shapes are in Black colour. The cytoarchitectural components of the liver appeared normal though with few heamorrhagic points.
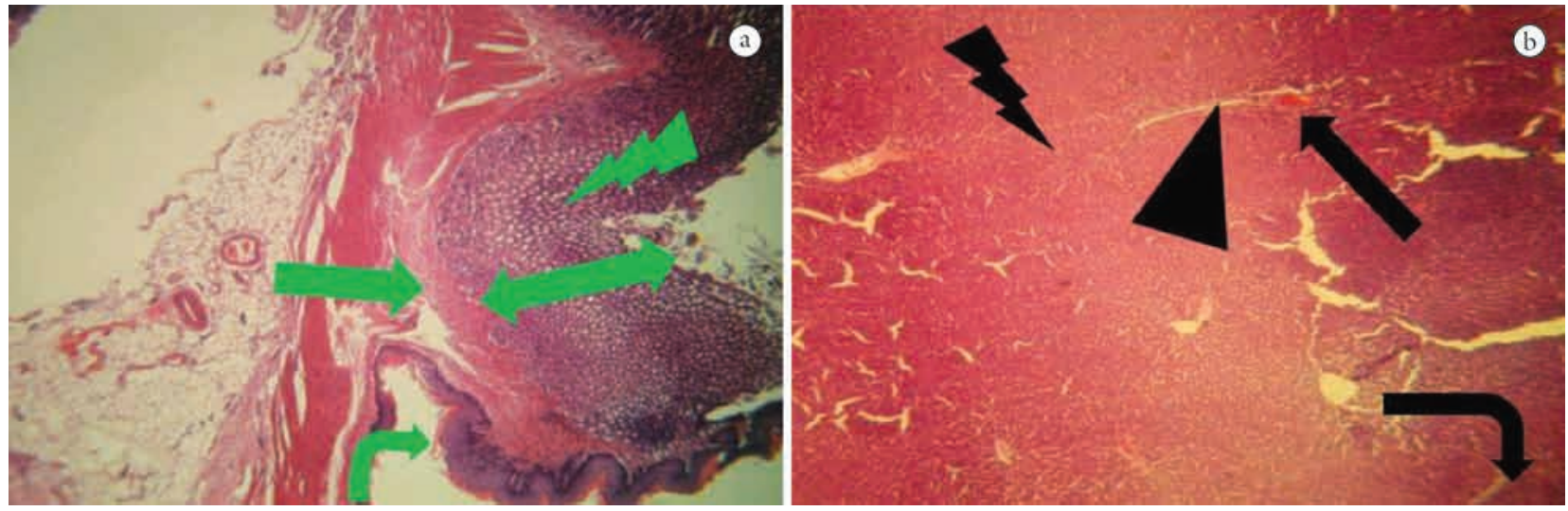

Figure 6. a) Photomicrograph sample of the liver of rats of Group VI treated with. $40 \mathrm{mg} / \mathrm{kg} /$ bodyweight of Omeprazole. Heamatoxylin and Eosin X 100. Up-Down arrow extends through the length of gastric mucosa layer, Bent arrow points to gastric pits and glands, Arrow points to muscularis mucosae and the Lightning Bolt points to peptic cells. All identification shapes are in Green colour. The cytoarchitectural components of the stomach appeared normal indicating regeneration of disrupted mucosa following Indomethacin-induced gastric ulceration. b) Photomicrograph sample of the liver of rats of Group VI treated with $40 \mathrm{mg} / \mathrm{kg} /$ bodyweight of Omeprazole. Heamatoxylin and Eosin X 100. Bent arrow points to kupffer cells, Arrow points to central vein, the Lightning Bolt points to hepatic cells and the apex of the Triangle points to a sinusoid. All identification shapes are in Black colour. The cytoarchitectural components of the liver appeared normal.

\section{References}

AKINLOLU, AA., SADIQ, M., AYOOLA, MD., OTULANA, JO., ABIMBOLA, O. and EJIWUNMI, AB. Morphological gastroprotective effects of Heliotropium indicum on gastric ulcerated mucosa. Pakistan Journal of Pathology, 2006, vol. 17, n. 2, p. 60-64.

AKINLOLU, AA., AYOOLA, MD., OTULANA, JO., AKINOLA, OB., ABIMBOLA, O. and EJIWUNMI, AB. Evaluation of the histo-gastroprotective and antimicrobial activities of Heliotropium indicum. Malaysian Journal of Medical Sciences, 2008, vol. 15, n. 3, p. 22-30. PMid:22570586 PMCid:PMC3341904.

BORRELLI, F. and IZZO, AA. The plant kingdom as a source of anti-ulcer remedies. Phytotherapy Research, 2000, vol. 14, n. 8, p. 581-591. http://dx.doi.org/10.1002/10991573(200012)14:8<581::AID-PTR776>3.0.CO;2-S
GBOLADE, A., EKOR, MN., AKINLOLU, A. and AYOOLA, MD. Antidiabetic activity of ethanolic extracts of spondias mombin stem bark on alloxan-induced diabetic rats. Journal of Pharmacentical Research, 2008, vol. 7, p. 192-195.

GBOlade, AA., AKINLOLU, AA. and ODEWABI, AO. Antihyperglycaemic and Hypolipidemic Activities of Stem bark ethanol extract of Spondias Mombin 1. (anacardiaceae). Nigerian Journal of Pharmaceutical Sciences, 2011, vol. 10, n. 1, p. 42-51.

JOHN, LW. How do NSAID's cause ulcer disease? Bailliere Clinical Gastroenterology, 2000, vol. 14, n. 1, p. 147-159. http://dx.doi. org/10.1053/bega.1999.0065

JOHN, AT. and ONABANJO, AO. Gastroprotective effects of an aqueous extract of entandro pragma utile bark in experimental ethanol-induced peptic ulceration in mice and rats. Journal of Ethnopharmacology, 1990, vol. 29, p. 87-93 
MAITY, B. and CHATTOPADHYAY, S. Natural antiulcerogenic agents: an overview. Current Bioactive Compounds, 2008, vol. 4, p. 225-244.

RAMZI, SC., VINAY, K. and TURCKER, C. Robbins' pathological basis of disease. 6th ed. Philadelphia: WB Saunders, 1999. p. 795796.

SABIHA, S., MOHD., AA., ASIF, M. and AKTAR, M. Roles of phenolic compounds in peptic ulcer: an overview. Journal of Pharmacentical Bioallied Science, 2011, vol. 3, n. 3, p. 361367. PMid:21966156 PMCid:PMC3178942. http://dx.doi. org/10.4103/0975-7406.84437
SEN, S., CHAKRABORTY, R., DE, B. and MAZUMDER, J. Plants and phytochemicals for peptic ulcer: An overview. Pharmacognosy Review, 2009, vol. 3, n. 6, p. 270-279.

SULEYMAN, H., ALBAYRAK, A., BILICI, M., CADIRCI, E. and HALICI, Z. Different mechanisms in formation and prevention of indomethacin-induced gastric ulcers. Inflammation, 2010, vol. 33, n. 4, p. 224-34. PMid:20084447. http://dx.doi.org/10.1007/ s10753-009-9176-5
Received July 152013

Accepted May 202014 